\title{
A SOBREVIVÊNCIA NO OLHO DO FURACÃO
}

\author{
Adriana Cruz dos Santos ${ }^{1}$ \\ Augusto Sarmento-Pantoja ${ }^{2}$
}

Resumo: Este estudo discute de que modo podemos conceber a sobrevivência após experiências traumáticas vividas por militantes políticos que lutaram contra a ditadura civil-militar brasileira pós-1964 e estiveram literalmente dentro do olho do furacão. A sobrevivência em si traz questões ambíguas em relação à construção dos testemunhos e, por isso, devem ser estudadas em seus pormenores. Utilizaremos para nossas análises dois documentários produzidos após a abertura política no Brasil, o primeiro de 1989, Que bom te ver viva, de Lúcia Murat, e o segundo de 2003, No olho do furacão, de Renato Tapajós e Tony Venturi. Entre aspectos destacados temos as formas estéticas dos filmes e a presença narrativa dos diretores nos filmes.

Palavras-chave: Sobrevivência, testemunho, documentário, ditadura.

\begin{abstract}
This paper discusses how we can conceive of survival after traumatic experiences lived by political activists who fought against the civil-military dictatorship Brazilian post-1964 and were literally in the eye of the hurricane. Survival itself brings ambiguous issues regarding the construction of statements and therefore should be studied in detail. We use our analysis to two documentaries produced after the political opening in Brazil, the first in 1989, Que bom te ver viva, for Lúcia Murat, and the second of 2003, No olho do furcão, for Renato Tapajós and Tony Venturi. Among the issues highlighted have aesthetic forms of narrative films and the presence of the directors in the movies.
\end{abstract}

Keywords: Survival, testimony, documentary, dictatorship.

\footnotetext{
${ }^{1}$ Graduanda em Letras na UFPA. Bolsista de Iniciação Científica PIBIC/UFPA. Membro do grupo de pesquisa ESPERHI e do projeto de pesquisa Performance e espetacularização da violência nas narrativas da memória traumática pós-64. E-mail: ambar.adriana@inbust.com.br

${ }^{2}$ Professor de Literatura Vernácula da UFPA. Doutorando em Teoria e História Literária na Universidade Estadual de Campinas (UNICAMP). Líder do grupo de pesquisa ESPERHI. Coordenador do projeto de pesquisa Performance e espetacularização da violência nas narrativas da memória traumática pós-64. Pesquisador do grupo de pesquisa Narrares. E-mail: augustos@ufpa.br
} 
Sobreviver não estava nos planos da maioria dos militantes de esquerda que se envolveram com a luta armada no Brasil, isso porque sobreviver significaria ser derrotado pelo regime civil-militar e compor um grupo de pessoas que perderam o direito à vida e passaram a uma condição de indivíduos para quem resta a sobrevida. Assim pensava a maior parte dos militantes esquecidos em suas sobrevidas, ou melhor, a vida que lhes sobrou, pois a vida de suas existências ficou para traz e para muitos precisava ser esquecida para sobreviver.

Sabemos de onde viemos; as lembranças do mundo de fora povoam nossos sonhos e nossas vigílias; percebemos com assombro que não esquecemos nada; cada lembrança evocada renasce à nossa frente, dolorosamente nítida. Não sabemos, porém, para onde vamos. Talvez sobrevivamos às doenças e escapemos às seleções, talvez aguentemos o trabalho e a fome que nos consomem, mas, $\mathrm{e}$ depois? Aqui, longe (por enquanto) das blasfêmias e das pancadas, podemos retomar dentro de nós mesmos e refletir, e torna-se claro, então, que voltaremos. (Levi, 1998, p. 54-55)

Esquecer e lembrar ou esquecer-se de lembrar para lembrar-se de esquecer, essas são algumas questões que salientam quando falamos de sobrevivência. As palavras de Primo Levi marcam o caminho da difícil tarefa de lembrar, ou melhor, de continuar lembrando quando a lembrança é tão destruidora, por isso, Levi destaca que não existe um testemunho "melhor" ou "pior" que o outro, pois:

Nenhuma experiência humana é vazia de conteúdo, de que todas merecem ser analisadas; de que se podem extrair valores fundamentais (ainda que nem sempre positivos) desse mundo particular que estamos descrevendo. Desejaríamos chamar a atenção sobre o fato de que o Campo foi também (e marcadamente) uma notável experiência biológica e social. (Levi, 1998, p. 88)

Essa experiência descrita por Levi potencializa um debate interessante sobre o testemunho, uma vez que o mesmo está contido na esfera da experiência humana e sua importância vai pautar as experiências de uma sociedade, de uma coletividade, por isso sai da esfera do drama individual e passa a expressar o drama coletivo; como afirma Valéria de Marco, o testemunho "reconstitui a história de um ou mais sujeitos escolhidos pela relevância que eles possam ter em um contexto social" (De Marco, 2004, p. 50). A relevância do narrador testemunhal pode ser construída na medida em que conseguimos garantir um espaço para essas memórias, como acredita Beatriz Sarlo (2007, p. 47):

A memória é um bem comum, um dever (como se disse no caso europeu) e uma necessidade jurídica, moral e política. Além da aceitação dessas características, é bem difícil estabelecer uma perspectiva que se proponha examinar de modo crítico a narração das vítimas. Se o núcleo de sua verdade deve ser inquestionável, também seu discurso deveria ser protegido do ceticismo e da crítica. A confiança nos testemunhos das vítimas é necessária para a instalação de regimes 
democráticos e o enraizamento de um princípio de reparação e justiça. Pois bem, esses discursos testemunhais, sejam quais forem, são discursos e não deveriam ficar confinados numa cristalização inabordável. Sobretudo porque, em paralelo e construindo sentidos com os testemunhos sobre os crimes das ditaduras, emergem outros fios de narrações que não estão protegidas pela mesma intangibilidade nem pelo direito dos que sofreram.

Foram 21 anos, amargados pelo Brasil, de ditadura militar que massacrou homens e mulheres no combate a esse regime cruel e desumano. Com a instalação do governo ditatorial, veio um estado de guerra e um forte esquema de repressão dimensionado pela tarefa militar de destituir, nos porões do DOI/CODI, o direito de sobreviver dos sobreviventes. Isso porque os órgãos de repressão foram extremamente eficazes na tarefa de retirar a dignidade daqueles homens e mulheres e deixar marcas indeléveis no corpo, na alma e principalmente nas mentes dos sobreviventes.

A recuperação dos testemunhos de militantes políticos que combateram a ditadura civil-militar no Brasil utilizou-se de um recurso bastante eficaz, o documentário. Estratégia que mistura documento, criação e ficção na tentativa de criar um espaço de legitimação do testemunho. É o que ocorre com os documentários Que bom te ver viva (QBTVV), de Lúcia Murat, e No olho do furacão (NOF), de Renato Tapajós e Toni Venturi, que expressam perfeitamente o conflito em função da angústia da sobrevivência, em um diálogo indireto com o espectador. Os filmes expõem uma perspectiva construída a partir dos depoimentos das personagens, fragmentos de histórias que se convergem a pontos comuns, expõem fatos reais organizados para que de alguma forma se estabeleça um enredo narrativo. Conforme compreende Soares o gênero documentário traz consigo a seguinte concepção:

Documentário é também resultado de um processo criativo do cineasta marcado por várias etapas de seleção, comandadas por escolhas subjetivas desse realizador. Essas escolhas orientam uma série de recortes, entre concepção da ideia e a edição final do filme, que marcam a apropriação do real por uma consciência subjetiva. (Soares, 2007, p. 20)

A apreensão da realidade histórica da ditadura civil-militar brasileira sob o olhar e a narração dos sobreviventes, que foram, de um lado, perseguidos e torturados e, de outro, os que foram perseguidos, mas não chegaram a ser presos, fomenta nos dois filmes o total de 12 entrevistas. Os entrevistados são os narradores de suas próprias histórias e o fazem no intuito de narrar para sobreviver e sobreviver para narrar, quase simultaneamente, como destaca Seligmann-Silva (2008, p. 66)

O testemunho como uma atividade elementar, no sentido de que dela depende a sobrevida daquele que volta do Lager (campo de concentração) ou de outra situação radical de violência que implica esta necessidade, ou seja, que desencadeia esta carência absoluta de narrar. Levi (...) coloca as expressões "aos outros" e "os outros" entre aspas. Este destaque indica tanto o sentimento de que entre o 
sobrevivente e "os outros" existia uma barreira, uma carapaça, que isolava aquele da vivência com seus demais companheiros de humanidade, como também a consequente dificuldade prevista desta cena narrativa.

Essa impossibilidade de elaborar o passado, tácito do testemunho da catástrofe nos é apresentado por Seligmann-Silva em Zeugnis e Testemonio: um caso de intraduzibilidade entre conceitos. Ao contrapor o testemunho da Shoah e o testemonio na América Latina Seligmann-Silva os diferencia por meio da necessidade de testemunhar, em uma acepção mais religiosa, ligada à punição de Deus para com o povo judeu, no caso da Shoah; e da necessidade de testemunhar para fazer justiça, nesse sentido, há a necessidade de dar a voz ao "subalterno" com vistas à criação de um herói exemplar, no caso do testimonio. Ambos são sobreviventes, mas em um observamos a predominância do ethos religioso tomando conta do discurso e no outro temos o ethos jurídico como potência discursiva mais evidente. Nesse sentido, ambas as formas narrativas estão marcadas por essa acepção de denúncia e justiça, diante da ausência da voz dos sobreviventes da ditadura civil-militar brasileira.

Para além dessas singularidades, o que mais difere nessas duas formas testemunhais? Podemos destacar as opções estéticas ali presentes: a primeira película, de Murat, foi construída sob o argumento de recuperar as vozes silenciadas de oito mulheres sobreviventes das prisões durante a repressão da ditadura civil-militar brasileira. Observamos que a diretora realizou uma seleção de narradoras que singraram por caminhos diversos, desde a escolha por viver em uma comunidade religiosa, passando por mulheres que encontraram na profissão sua fuga; chegando a continuidade da luta política no trabalho comunitário. Todas perpassadas por um mesmo sentimento a necessidade de suportar as lembranças dolorosas da memória traumática. A diretora costura essas narrativas testemunhais com a encenação dos sofrimentos de uma personagem anônima na difícil tarefa de sobreviver, traçando uma crítica ao modelo social que mesmo depois da ditadura continua alijando a memória dos militantes com a mácula do terrorismo. Ao mesmo tempo em que utiliza a voz da personagem anônima como a face da voz do narrador que procura assimilar os diversos narrares e as diversas conversas dessas narrativas, ao mesmo tempo síntese e antítese daquelas narradoras. Vejamos o que a personagem anônima criada por Murat narra em QBTVVV:

Observando do lado de fora, como um voyeur olha pela janela da vizinha, meu olhar é igual ao de todo mundo. E a história de Maria hoje, uma educadora que é casada e tem dois filhos parece não ter muito a ver com esse passado. Na maternidade, Maria diz ter resgatado a possibilidade de vida, mas isto explica ou encerra tudo? (QBTVV, 12'02" - 12'36")

Notemos que a narradora anônima de QBTVV, questiona a aparente sobrevivência de Maria mediada pela maternidade, para a narradora problematizar a opção de Maria em enterrar seu passado ao se perguntar se realmente este passado foi aniquilado pela memória ou seria apenas uma forma de garantir a sua sobrevivência por meio da sobrevida conquistada com a maternidade. O conflito se acentua no discurso da narradora quando se questiona "mas isso explica ou encerra tudo?". A narradora não acredita que a sobrevivência funda 
um fim para o sofrimento e a mácula deixada na alma daquelas mulheres por isso deixa evidente sua incredulidade diante da uma vida "normal" que passam representar aquelas mulheres.

Em outra passagem do testemunho de Maria do Carmo, fica evidente a necessidade de apegar-se na maternidade como forma de garantir a sobrevivência em meio ao terror que cada sobrevivente passa a viver no que resta de suas vidas:

eu descobri que esse tiro que eu dei neles era de saúde e me reconciliei com esta situação na minha primeira gravidez. Descobri que a melhor coisa do mundo era ser mulher. (...) E agente produz vida, uma coisa... Não é uma frase, nem um troço intelectualizado, foi uma descoberta tão bonita. Ai que eu descobri que ser mulher era o maior barato. (QBTVV, 10'23" - 12'00”)

Para a narradora de QBTVV há uma posição de afastamento em relação ao evento traumático, peculiar aos narradores testis, o que garante certa isenção para analisar o que se passa na narrativa do trauma, ao formalizar estratégias de sobrevivências que possam afastá-las cada vez mais de seu passado, seja para se proteger ou para proteger seus familiares, dessa forma narrar não seria mais fundamental, mas sobreviver, como sinônimo de esquecimento, como observamos no depoimento de Estela Bohadana:

Eu tenho um filho de 10 anos e um que vai fazer 15, mas o que eu sinto, nos dois, é que embora, o fato de eu ter sido presa ter sido torturada, incomode, crie uma certa revolta, eles preferem que eu não fale. Quer dizer, eu sinto que é um assunto que incomoda tanto, que é melhor que se esqueça. Eu acho que, eles de alguma forma reivindicam que eu esqueça, talvez para que eles mesmos não entrem em contato com uma coisa tão dolorosa. (QBTVV, 20’21" - 20'56”)

Observamos neste testemunho que Estela Bohadana acirra em seu discurso o conflito da duplicidade existente na construção do testemunho, uma vez que formalizar um testemunho representa fazer escolhas na difícil tarefa de lembrar e esquecer, já que a condição de sobrevivente de experiências traumática promove uma exasperação da dimensão do sofrimento, pois contraditoriamente necessita testemunhar, narrar o que aconteceu, mesmo tendo necessidade de esquecer partes dessa narrativa como forma de proteger-se do horror que essas lembranças lhe causam.

Não há como alijar da sua existência tais experiências, ao mesmo tempo as lembranças são entrecortadas por vazios que o próprio narrador testemunhal não consegue explicar. Observamos, assim, que o narrador testemunhal passa a compreender que construiu uma identidade nova, tão marcante quanto à antiga, de combatente, que representa não mais aquele passado, e sim um misto de suas lembranças e a necessidade de suportar as consequências terríveis e inesquecíveis daquele passado, que até hoje está presente. SeligmannSilva afirma que esta necessidade de testemunhar faz referência a chave do trauma, a uma necessidade de justiça e de dar conta da exemplaridade do herói e de conquistar uma voz, silenciada e oprimida, no caso de Estela. 
Utilizando outra estratégia o filme de Renato Tapajós propõe mostrar que a luta contra a ditadura militar se desdobrou na busca por um lugar na sociedade que verbere sua proposição resistente. Nesse sentido, as quatro pessoas que fazem parte do documentário de Tapajós fomentam o imaginário de que "tudo vale a pena quando a alma não é pequena", como perifraseia Dulce Maia em depoimento emocionado sobre sua condição resistente. A narrativa de No olho do furacão, é formada pelo depoimento de dois homens e duas mulheres e busca apresentar um cenário militante da história e do cotidiano de heróis que sobreviveram na luta contra a ditadura no Brasil.

Os diretores Tony Venturi e Renato Tapajós exploram caminhos diferentes na condução desse documentário, pois encontramos um comprometimento tamanho de Renato Tapajós com o projeto de recuperação do heroísmo dos militantes incluindo-se nas cenas, acompanhando os entrevistados como parte desses depoimentos, já que Renato também é um sobrevivente e hoje delega sua história ao compromisso de narrar cinematograficamente o valor das ações e dos homens e mulheres comprometidos com a luta contra a ditadura no Brasil. Por isso, antes de tudo, os diretores criam um efeito de comprometimento com aquelas histórias e sua função revolucionária na contemporaneidade. Assim encontramos: revolucionário que após a abertura recupera seus direitos civis e políticos e se volta à política partidária; revolucionário que continua na resistência, mas sob outro viés, uma resistência ligada à compaixão e ao trabalho voluntário; por último, um revolucionário que sai de dentro do sistema repressivo e que de certa forma continua sua relação com o estado repressor como adestrador de cães da polícia militar do estado de São Paulo.

Histórias que os confinam, ao mesmo tempo, completam suas existências, mas que associados a isso representam a sobrevivência, não mais como derrota, e sim como esperança de quem precisa trabalhar para mudar o mundo, seja na política, no trabalho voluntário ou na formação de um contingente não humano para lutar pela ordem social.

O passado heroico dos militantes é descrito com detalhes, mostrando, entre outras coisas, as dificuldades vivenciadas por eles durante a resistência e o compromisso daqueles homens e mulheres com o movimento, como no testemunho de Carlos Eugênio Paz (Clemente):

Não podia fazer nenhum barulho, porque oficialmente os dois companheiros que moravam na casa saíram para trabalhar (...) quando vinham de noite traziam sanduiche e coca-cola, coca-cola quente... aquela coca-cola que já veio do botequim gelada, mas até chegar em casa tava quente e sanduíche de mortadela. Aquelas coisas barata que a gente podia comprar porque o dinheiro ali não era... O dinheiro custava sangue, né nosso, nós era muito espartanos nessas coisa, a gente não gastava dinheiro, assim sabe, era uma coisa assim de princípio nossa, né, a gente não cuidava do bem estar da gente primeiro. (NOF, 14'06" - 14'39")

O valor do dinheiro e a necessidade de valorizá-lo ficam latentes na passagem acima. O mesmo ocorre no testemunho de Robêni da Costa (Rosângela) que, de certa forma, aponta o quanto era necessário para manter a sobrevivência do movimento, os sacrifícios alimentares, pois como nos mostrou Clemente "o dinheiro custava sangue". 
O dinheiro era muito curto era só o dinheiro que vinha pra fazer a manutenção do aparelho e vinha da organização e era o Alcides que fazia a comida, ele cozinhava. E a comida era... contar não dá pra acreditar, mas era assim, era arroz, arroz que japonês gosta que chama gohan e era uma sardinha que a gente comprava no mercado de pinheiros aquela sardinha seca salgada e ele punha pra perder um pouco de sal, depois fritava e a gente comia aquilo, semanas e semanas (NOF, $\left.14^{\prime} 57^{\prime \prime}-15^{\prime} 37^{\prime \prime}\right)$

O filme é marcado por uma pesquisa de arquivo e traça dois momentos das vidas das personagens como se quisesse desnudar as facetas do terror e da sobrevivência, pois cada entrevistado será direcionado para discorrer sobre seus traumas e dores, de um lado; de outro, as alegrias e satisfações do cotidiano resistente durante suas experiências na luta contra a ditadura civil-militar pós-1964 e seu cotidiano após a anistia.

Essa luta contra a ditadura civil-militar brasileira construiu espaço para o testemunho e denúncia das atrocidades promovidas pela ditadura no Brasil com mais liberdade após a anistia política, que terá uma dupla função no cenário ditatorial, de um lado permite que exilados políticos retornem para o Brasil, promovendo o perdão irrestrito dos crimes a eles atribuídos. De outro lado, garante a impunidade para com as atrocidades praticadas contra a sociedade em nome da Lei de Segurança Nacional, assim como silencia toda e qualquer forma de denúncia contra o estado brasileiro, que abdicou de suas responsabilidades para com as torturas, os sequestros, os ocultamento e desaparecimento de corpos.

A crítica reservada à anistia se tornou pano de fundo do filme Que bom te ver viva, onde Lucia Murat propõe um debate sobre a sobrevivência e a manutenção da dignidade feminina após experiências extremas de violência, dor e sofrimento. Esse documentário foi um dos primeiros filmes realizados no Brasil após a abertura política. Em No olho do furacão, temos também certa crítica de como a anistia foi cruel para com os sobreviventes, porque impedia que homens e mulheres pudessem ser reconhecidos como testemunhos de luta e sobrevivência.

Ambos documentários foram dirigidos por testemunhas vivas da resistência, o que marca o compromisso desses autores com uma reescritura da história, como salienta Walter Benjamin ao descrever a necessidade de ler a história a contrapelo, desmascarando as versões da história cristalizadas pelo poder. O testemunho das mulheres, em ambos, foi marcado pela culpa diante da derrota e o desejo de desforra diante da crueldade de seus torturadores.

Lúcia Murat foi presa e violentamente torturada no DOI-CODI, onde permaneceu durante dois meses e meio. Por meio da linguagem cinematográfica, abre um espaço para que sobreviventes desse horror possam tirar do esquecimento o assassinato de seus entes queridos, o que foi a tortura e, sobretudo, como vivenciam estes acontecimentos e sua dificuldade de lembrar e narrar, como demonstra Maria do Carmo:

O que é que foram aqueles 60 dias... é muito... parece que foram 60 anos, isso eu já disse, não dá pra descrever. É uma coisa terrível, porque... é uma luta constante para você se manter inteiro. Eu nem lembro que eu estava menstruada. Eles então 
para me pendurar no pau-de-arara em consideração em ser uma senhora, me punham uma calça nojenta. Uma calça de homem toda suja de tudo quanto era coisa. E eu ficava pendurada com aquela calça. Porque começou a pingar e eles disseram que não estavam a fim de ver aquele espetáculo puseram a calça. Ai de vez em quando eles me pegavam com a calça e tudo e me jogava dentro de um aquário que tinha ali numa outra sala, depois pegava e tornava a pendurar no pau-de-arara. Isso durou até... eu não me lembro bem, é tudo muito confuso. Só me lembro que teve uma hora que... é... tavam tirando a minha pressão, e o outro sujeito dizia assim, pode continuar pressão de atleta, pode continuar! (QBTVV, $\left.12^{\prime} 38^{\prime \prime}-13^{\prime} 46^{\prime \prime}\right)$

A obra de Murat retrata e reconstrói artisticamente a memória dos oprimidos durante a ditadura civil-militar brasileira pós-64. Com isso, seleciona aquilo que se deseja discutir e compartilhar com o espectador. Essa seleção alimenta o debate relativo ao conflito ficção/ realidade proposto pelo cinema documentário. Neste sentido, a própria estratégia de construção narrativa entrelaça o testemunho nos liames entre o ficcional e o real. Nesse caminho, realidade e ficção costuram o espaço do documentário destituindo o leitor do liame que separa a realidade da ficcionalidade. Assim como afirma Marialva Barbosa (2007, p. 17):

Se o passado for visualizado como algo que pode ser recuperado, as fontes, documentos e emblemas do passado que chegaram até o presente, sob forma de rastros, serão privilegiados na interpretação. Se por outro lado, considera-se que o que chega do passado são vestígios memoráveis, permanentemente reatualizados pelas perguntas que do presente são lançadas ao pretérito, o que será destacado é a capacidade de invenção da narrativa. Ou seja, não se pode eliminar a categoria interpretação da história, da mesma forma que a história será sempre uma narrativa.

Ao assistir QBTVV se percebe a presença ideológica da autora como aquela que constrói a narrativa, mesmo sem aparecer no filme. Sua presença é marcada pela voz da narradora e pela presença da personagem fictícia. Lúcia Murat ao escolher os fragmentos que serão apresentados ao espectador altera o estado pacífico do leitor, impondo-lhe uma necessidade de reflexão sobre tais testemunhos. As ações performáticas dessas narradoras testemunhais tanto no filme de Murat quanto no filme de Renato Tapajós expressam em suas narrativas "segredos" revelados de um passado difícil e passível de ser superado, mas que as câmeras e todo aparato técnico que requer uma filmagem pressupõem uma observação de si, fazendo com que a narração seja anteriormente pensada para que diante da câmera e do diretor seja dado seu depoimento. Desse modo, torna-se relevante a proposição de Marialva Barbosa ao considerar que:

Performar é realizar uma ação artística no tempo e no espaço. Porém, não é só a qualidade efêmera de seus atos que a caracteriza e sim a emergência de um ato criativo como articulador de processos estéticos, humanos e/ ou sociais em momento presente. (Barbosa, 2007, p. 1). 
A performance enquanto ação está presente na atuação da atriz, que interpreta a personagem anônima, voz que não cala, fala direto para a câmera que filma, dialoga diretamente com o espectador, incluindo sua participação performática. Porém percebe-se que cada uma das oito mulheres, em detrimento a personagem ficcional, tem dificuldade de encarar a câmera e contar suas dores. A personagem anônima não narra somente, convida o espectador a fazer parte da ação reflexiva e interativa durante a ação cênica que envolve o documentário, mesmo quando o cerne do debate seja a necessidade de narrar contrastando com a urgência de esquecer. Nesse caminho, a performance dessas testemunhas será próximo ao que Jorge Glusberg (2005, p. 65) irá defender em $A$ arte da performance, quando analisa que ela "é fonte de numerosos fantasmas psicológicos que tocam a interioridade do sujeito e põem em crise sua estabilidade; estabilidade - literalmente falando - que se fundamenta na repetição normalizada de convenções gestuais e comportamentais".

Quando eu fiquei grávida e aí eu tava até fazendo terapia... e aí... o terapeuta disse agora eu acho que você já está bem, vai embora pra casa, vai ter seu filho vai, criar seu filho. Porque é uma vida nova que surge, é uma esperança grande que vem junto. E aí você se desloca do social para o individual e ai vai viver uma outra coisa. (Pupi, QBTVV, 33'30" - 34’01")

As paixões e o pensamento ideológico formaram as bases do envolvimento na situação política do país por parte destes jovens de 64. O desejo de revolucionar, viver na clandestinidade e se fosse preciso matar, mas sem dúvida, viver o limiar entre a vida e a morte. A certeza de estar promovendo o bem para a humanidade contra o mal avassalador que representava a ditadura civil-militar. As máculas deixadas pelo insucesso da ação deixaram marcas perceptíveis em todos os depoimentos apresentados, traumas que se amargam também pela lembrança dos que morreram, como se pode observar na fala de Carlos Eugenio Paz em No olho do furacão, por exemplo. Ao sobreviver, a convivência com o trauma do sofrimento deixa a ideia de uma presença recorrente, um conflito entre o sobrevivente de hoje e memória do jovem combatente que foi no passado, aquele que lutou e perdeu! Humilhações imponderáveis da tortura que não se pode esquecer. Lúcia Murat em Que bom te ver viva, disponibiliza a imagem deste conflito no depoimento da mãe de Maria do Carmo numa perspectiva, enfim "positiva", de que no final a filha supera o insuperável:

No principio a vida dela foi muito difícil, ela tinha pesadelos incríveis, alucinações, sofreu muito... O médico do Chile chegou a me dizer que se ela houvesse perdido uma mão, um dedo, seria fácil, porque a gente veria o problema, mas não o que ela perdeu foram células cerebrais, isso dificultou muito no princípio e para a vida dela. Felizmente ela superou tudo isso, e hoje ela educa muito bem os seus filhos e, sobretudo, ela guarda uma grande coerência de vida (QBTVV, $\left.14^{\prime} 13^{\prime \prime}-14^{\prime} 49^{\prime \prime}\right)$

Havia na maioria dos relatos apresentados a experiência da mudança de nome, uma nova identidade construída para ser militante. Robêni da Costa se tornou Rosângela, Carlos Eugênio virou Clemente. Identidades que estabeleceram outros padrões de comportamento, 
de clandestinos no próprio país, sem referência de amigos ou família, cumprindo ordens, sem divulgar endereço. Mas como todo jovem, estudava, trabalhava e namorava. Esse comportamento natural da juventude foi um caminho destacado por Tapajós e Venturi para combater os contínuos discursos corrosivos de terroristas, que assombravam seus cotidianos. Eles viveram intensamente! Talvez este seja um aspecto relevante no filme de Renato Tapajós, o de que os entrevistados se apresentam fora do estereótipo de brutalidade e falta de alegria. Eles se apresentam como estudantes e trabalhadores preocupados com o próximo, sonhando com o futuro que teriam - preferencialmente em uma sociedade melhor. E isto se observa nos relato de Carlos Eugênio:

A gente entrava num carro bicho, era piada, era brincadeira entendeu, era um clima de camaradagem total, total, completamente fraterna, agente na reunião num aparelho assim, agente fazia verdadeiras festas, com macarrão com sardinha, vivia no dia-a-dia da cidade e da rua, entrando no butiquim ali, saber onde que é não sei o que. Sabe, vivia, não era uma coisa assim, não vivia completamente escondido, agora a minha casa ninguém sabia onde era, só eu e minha mulher e se eu tava morando sozinho só eu é que sabia. (NOF, 21'46”-22’16”)

A condição resistente vivida pelos entrevistados fica marcada em No olho do furacão como um cotidiano que se aproxima ao dos demais jovens, mas possuíam particularidades pouco entendíveis quando não se está vivendo sob um regime de exceção como foi a ditadura civil-militar brasileira. Vejamos o exemplo apresentado por Clemente sobre as relações afetivas entre os membros do grupo:

Mas tinha tudo isso, tinha amor, tinha ódio, tinha relação mal resolvida, tinha relação bem resolvida, tinha, tinha gestos tão incríveis, mas tão incríveis, você ai imaginou, e ai toca um pouco naquela no começo da história da revolução sexual e do amor livre, aquela coisa toda né.... tinha momentos em que... teve momentos em que de repente, teve um caso concreto que eu conheço de uma companheira que tava morando com o companheiro, apaixonado por um companheiro, que de repente o companheiro quis acabar a relação, então tavam no mesmo aparelho e disse que estava querendo acabar porque estava apaixonado por outra companheira entendeu, e de repente essa companheira chegar e dizer assim poxa, traz ela pra cá. E essa companheira ir pra lá e a outra companheira ceder a cama pros dois dormirem juntos e fazerem amor. (NOF, 22'17" - 23'14")

A relação aberta proposta na militância lembra bastante o cenário de companheirismo das comunidades alternativas de hippies, que de certa maneira reforçam o desejo utópico dos jovens de construir um mundo melhor, onde as questões amorosas bem demarcadas pelos princípios do casamento burguês pudessem ser substituídas pelos princípios do amor livre, mais próximos do pensamento socialista que pautava os movimentos de resistência.

Dulce Maia afirma ainda que foi a primeira mulher a sofrer tortura, violência no Brasil. Quando faz esta afirmação, aproxima seu depoimento daqueles contidos no filme de 
Murat. A dura situação feminina nesta história, a condição da maternidade e da violência inclusive sexual traz à memória inúmeras situações de mulheres grávidas que abortaram em sessão de tortura; para saber, basta acessar sites na internet preocupados em divulgar estes crimes. Mas Lúcia Marat não divulga, ela questiona as possibilidades da torturada, de como a condição de mãe pode ou não restabelecer algum pertencimento ao meio social, se para tanto urge a necessidade de se identificar com este meio, com o qual esta mulher já não se identifica. Dulce afirma:

Eu fui a primeira mulher a ser presa no Brasil, desse período, desse período sim, e fui muito maltratada justamente por isso, porque eu ser mulher, por eu ser de uma classe social diferente. Como? Eu era uma traidora para eles, eles me trataram assim, exatamente assim, eles diziam isso. Na época também havia todo um ódio assim uma coisa te... violenta contra um que era muito meu amigo, é até hoje muito meu amigo Chico Buarque, Vandre que também era muito amigo, então eles queriam muito saber sobre eles. Eu vinha do teatro oficina, que tinha acabado de montar o Rei da Vela, Caetano, Gil também, o tropicalismo todo nasceu ali naquele momento. Eu era pra eles [a polícia] considerada um estudante, mesmo eu não sendo um estudante, porque eles tinham muito ódio aos estudantes também, então eles achavam inclusive que eu pertencendo a uma outra classe eu devia estar ligada aos estudantes e nunca deveria estar ligada a sargentos, a cabos, e..., mas a traição minha era uma traição de classe, muito maior... (Dulce Maia/Judith)

As obras artísticas produziram ao longo da história da humanidade representações, indagações e questionamentos imbuídos de ética e estética, nas quais ao mesmo tempo em que as condições emocionais e afetivas do espectador são acessadas, o seu comprometimento lógico-racional também. Estas obras são capazes de atribuir sentidos catárticos enquanto elemento da relação com a arte, pelo modo aristotélico ou pelo modo nietzschiano do conceito da catarse, processo vivido por aquele que se vê diante de uma obra cujo enredo é o sofrimento humano. Desta forma os filmes Que bom te ver viva e No olho do furacão impelem atributos de narrativa artística de qualidades que se aproximam dos memoriais e da performance efêmera e insubstituível no tempo e no espaço. Mesmo que os filmes se constituam de fragmentos de vida real ou espelhamento do real, vimos ao longo desta análise que podemos considerar os documentários como obras artísticas fílmicas, porque não dizer autorais e singulares, no campo artístico principalmente, pela representação da realidade e pelos sentidos que as obras adquirem. E sem dúvida, cada um dos documentários aqui comentados traz o recurso da mobilização, da participação do espectador para uma negação da tortura e da violência contra a liberdade do pensamento humano. Neste sentido, tais filmes são exemplares da sobrevivência do testemunho de quem um dia esteve imerso no olho do furacão. 


\section{REFERÊNCIAS}

BARBOSA, Marialva. Vestígio do tempo: história cultural da imprensa brasileira e práticas sociais de leitura. Lisboa: Revista Portuguesa de História do Livro, 2007.

DE MARCO, Valeria. A literatura de testemunho e a violência de Estado. Lua Nova, no 62, 2004, p. 4568. Disponível em: http://www.scielo.br/pdf/ln/n62/a04n62.pdf. Acesso em 21/08/2013.

GLUSBERG, Jorge. A arte da performance. Tradução de Renato Cohen. São Paulo: Perspectiva, 2005.

LEVI, Primo. É isto um homem? Tradução de Luigi Del Re. Rio de Janeiro: Rocco, 1988.

SARLO, Beatriz. Tempo passado: cultura da memória e guinada subjetiva. Tradução Rosa Freire D’Aguiar. São Paulo: Companhia das Letras; Belo Horizonte: UFMG, 2007.

SELIGMANN-SILVA, Márcio. Zeugnis e Testemonio: um caso de intraduzibilidade entre conceitos. Revista Letras. № 22. Jun/Jan 2001. Disponível em: http://w3.ufsm.br/revistaletras/artigos_r22/11_ marcio_silva.pdf. Acesso em 20/08/2009.

SOARES, Sérgio José Puccini. Documentário e roteiro de cinema: da pré-produção à pós-produção. 2007. 250 f. Tese (Doutorado em multimeios) - Universidade Estadual de Campinas, Campinas, 2007.

FILMOGRAFIA

QUE BOM te ver viva. Direção de Lúcia Murat. Rio de Janeiro: Taiga Filmes e Vídeo, 1989.

Documentário (100 min.), son., color.

NO OLHO do furacão. Direção de Renato Tapajós e Tony Venturi. São Paulo: Olhar Imaginário, 2003.

Documentário (52 min.), son., color. 